\title{
Heterogeneity of Tissue Dehydrogenases ${ }^{1}$
}

\author{
MAKEPEACE U. TSAO \\ From the Department of Pediatrics and Communicable Diseases, University of \\ Michigan Medical School, Ann Arbor, Michigan
}

Received March 28, 1960

\begin{abstract}
Rat tissue homogenates have been subjected to zone electrophoresis in starch gel. Lactate, malate, isocitrate, glucose 6-phosphate, and $\alpha$-glycerophosphate dehydrogenase activity was directly visualized by incubating the gel strips in solutions containing a specific substrate, a tetrazolium salt, methylene blue, and the appropriate pyridine nucleotide. Electrophoretic heterogeneity of some of the dehydrogenases was observed in material from different organs. A similar multiplicity of components in some specifie dehydrogenases was also demonstrated in cytolngically homogeneous material including cells grown by tissue culture techniques. Significance of this multiplicity of enzymes is discussed.
\end{abstract}

\section{INTROIDUCTION}

The existence of more than one active component in a purified dehydrogenase has been shown by Neilands (2) and Krebs (3). The numerous steps required in the preparation of pure enzymes raised the question of whether the components had been derived from what was originally a single-component enzyme. When human serum was found to contain multiple components of lactate dehydrogenase by Sayre and Hill (4), and malate dehydrogenase as well by Vesell and Bearn (5), it began to appear that perhaps dehydrogenases can exist in electrophoretically distinct forms. Unfortunately, the origin of these two dehydrogenases of serum is not known; hence, the possibility still remains that only a single component was synthesized in the cells but gave rise to multiple active forms on its way to the blood. Wieland and Pfleiderer (6) studied the homogenates of animal organs with paper electrophoresis and found numerous components of lactate dehydrogenase in

1 Supported in part by an Institutional Research Grant to the University of Michigan from the American Cancer Society and by Funds from the University of Michigan Cancer Research Institute. A preliminary report has been published (1). most of the organs. Again, the presence of multiple forms of lactate dehydrogenase in tissues seems likely. Since the tissues are such a conglomeration of various cell types, it is possible that this multiplicity of enzymes might be attributed to different types of constituent cells. This phenomenon is, by itself, interesting. However, before this postulation can be made, it is necessary to know whether the multiplicity of dehydrogenases exists in preparations of a single-cell type.

This paper reports a study of the fractionation of several dehydrogenases of rat tissues, and highly homogeneous cell preparations including those grown by tissue culture. The enzymes of the tissue or cell homogenates were fractionated by zone electrophoresis in starch gel, and the loci of the active dehydrogenases that were confined in discrete bands in the gel were directly visualized. This was made possible by incubation of the gel in a solution containing a substrate, pyridine nucleotide, other cofactor, and a tetrazolium salt. The series of reactions apparently begin with the reduction of the pyridine nucleotide and end with reduction of the tetrazolium salt to form a precipitate of highly colored and insoluble formazan. 


\section{FXPERIMENTTAL,}

\section{Materials}

Hydrolyzed starch was obtained from the Connaught Medical Research Laboratories, University of Toronto. Isocitric acid (lactone) was purchased from the California Foundation for Biochemical Research. Malic acid and glutamic acid were supplied by Jistillation Products Industries. Jactic acid was from Merck \& Company, Inc. (ilucose and succinic acid were obtained from Ceneral Chemical Division, Allied Chemical \& Dyo Corporation. Potassium $\alpha$-glycerophosphate was from Eastem Chemical Corporation. $\beta-\mathrm{Hy}$ droxybutyric acid, $\alpha$-ketoglutarie acia, potassium glucose 6-phosphate, DPN, and TPN were supplied by the Sigma Chemical Company. Tris (hydroxymethyl)aminomethane was from (A. Frederick Simith Chemical Company. Cilycylglycine, diaphorase, and neotetrazolium chloride were purchased from the Nutritional Biochemicals Corporation.

Solutions for the direct visualization of dehydrogenase activity of the enzymes in the starch gel were prepared shortly before use. The final concentrations of the solutions are given below.

For lactate or malate dehydrogenase:

substrate, neutralized sodium salt, $0.02 \mathrm{M}$; Tris. HCl buffer, $0.05 \mathrm{M}, \mathrm{pH} 8.4$; I)PN, $0.0003 \mathrm{M}$; $\mathrm{KCX}, 0.015 \mathrm{M}$; methylene blue, $0.0005 \mathrm{M}$; and neotel razolium chloride, $0.0003 \quad M$.

For isocilrate dehydrogenase:

Subst rate, hydrolyzed lactone, $0.005 \mathrm{M}$; glycylglycine buffer, $0.05 M, p H \quad 7.4$; TPN, $0.0004 M$; $\mathrm{MnCl}_{\Perp}, 0.001 \mathrm{M}$; KCN, $0.015 \mathrm{M}$; methylene blue, $0.0005 \mathrm{M}$; and neotetrazolium chloride, $0.0003 \mathrm{M}$.

For glucose-6-phosphate dehydrogenase:

Substrate, potassium salt, $0.001 \mathrm{~K}$; glycylglyeine buffer, $0.05 \mathrm{M}, \mathrm{pH} 7.4$ : TPN, $0.00005 \mathrm{M} ; \mathrm{MgCl}_{2}$, $0.005 \mathrm{M}$; $\mathrm{KCN}, 0.015 \mathrm{M}$; methylene blue, 0.0005 $M$; and, neotetrazolium chloride, $0.0003 \mathrm{M}$.

For a-glycerophosphate dehydrogenase: Substrate, potassium salt, $0.02 \mathrm{M}$; Tris. $\mathrm{HCl}$ buffer, $0.05 . \quad h ; \mathrm{pH} 8.4$; DPN, $0.003 \mathrm{H}$; Versene, 2 $\mathrm{mg} . / \mathrm{ml}$; $K \mathrm{CN}, 0.015 \mathrm{M}$; methylene blue, 0.0005 $M$; and, neotetrazolium chloride, $0.0003 \mathrm{M}$.

During the preparation of the above solutions, and before heat-labile material was added, $7 \%$ $w / v$ of hydrolyzed starch was introduced. By heating just to boiling, a sirupy solution was obtained. After this solution was cooled to about $40^{\circ}$, the heat-labile constituents were then dissolved. The solution was poured into a long, narrow tube $(1.2 \mathrm{~cm} . \times 21 \mathrm{~cm}$.) and was kept warm until needed. The solution thus prepared remained liquid while starch gel strips containing enzymes were inserted; it became a gel when the tube containing the complete system was chilled in an ice bath.

Tissue homogenates were prepared fresh from perfused organs from male Sprague-Dawley rats. One volume of tissue and four volumes of a $1 \%$ solution of a surface-active agent, "Surfactol" $\left(\mathrm{R}\left(\mathrm{CH}_{2} \mathrm{O}\right)_{x} \mathrm{CH}_{2} \mathrm{OH}\right)$, were ground in a PotterElvehjem homogenizer. Temperature throughout this procedure was maintained at $0^{\circ}$.

Cells grown by tissue eulture technique were kindly supplied by the following colleagues: IDr. Francis F. Payne, HeLa cells; Dr. Donald J. Merchant, mouse fibroblast cells grown by monolayer or suspension technique; Dr. James F. Hogg, mouse ascites lymphoma cells; I)r. Peter P. Ladovici, a strain from carcinoma of human ovaries and human amnion cells. The cells were washed by repeated suspension and centrifugation in saline. A homogenate of washed cells was prepared by grinding in 'lis. $\mathrm{HCl}$ buffer with mortar and pestle at $0^{\circ}$.

\section{Methons}

\section{Fractionation of Dchydrogenases in Homog- enates by Zone Electrophoresis}

The technique of Smithies for zone electrophoresis in starch gel, originally developed for the fractionation of sorum proteins, was adapted for the fractionation of enzymes in this study (7). The gel was prepared, however, in $0.03 \mathrm{M}$ Tris. $\mathrm{HCl}$ buffer of $\mathrm{pH} 8.4$ in the plastic tray. Twenty microliters of the homogenate was placed on a piece of filter paper the size of the cross section of the starch gel column and inserted into a slit cut in the gel. The circuit for electrophoresis consisted of a d.c. power source generating $400 \mathrm{v}$, plat inum electrodes, $0.05 M$ Tris. $\mathrm{HCl}$ buffer baths, and filter-paper pads as bridges connecting the electrodes with the starch gel column in the tray. A thin plastic film was used to cover the tray to prevent evaporation. To maintain the temperature of the columm at $0^{\circ}$ during electrophoresis, a glass tray containing ice was placed over it. An electric potential of $10 \mathrm{v} . / \mathrm{cm}$. was applied to the gel column for $5 \mathrm{hr}$.

\section{Direct Visualization of Dehydrogenase Activity in the Starch Gel Column}

At the end of electrophoresis, the filter paper containing the sample was removed and the starch gel column was sliced longitudinally along the side of the tray into strips of $5 \mathrm{~mm}$. width. The strips were gently lifted and placed in the tubes containing various warm incubation media. The tubes were stoppered, chilled in an ice-bath to set the medium into a gel, and incubated at $37^{\circ}$ in 
the dark. The gelled medium remained semisolid during the incubation. Incubation lasted from several hours to several days, and was terminated by rinsing the strips free of the medium before dark-blue bands became wide or diffused. After the incubation has been completed, and the starch gel strips have been rinsed free of methylene blue by repeated change of tap water in a tube, they can be preserved in cold water indefinitely without fading of the red bands which represent the sites of dehydrogenase activity.

\section{RESLLTS}

When rat tissue homogenates or homogeneous cell preparations were processed as described in Methods, various numbers of dehydrogenases were detected for each substrate used. These enzymes were represented by discrete bands in the starch gel columns. In general, malate dehydrogenases activity became noticeable in a matter of hours; lactate and isocitrate dehydrogenase activity became detectable after $12-24 \mathrm{hr}$. of incubation; and, glucose 6-phosphate and $\alpha$-glycerophosphate dehydrogenase activities required 1-i3 days to become visible as dark bands on the starch gel column. The results of the fractionation of various dehydrogenase activities of rat tissue homogenates followed by direct risualization are summarized graphically in lig. 1. The starch gel strips are shown with the electropositive end to the left, a gap to the right of center indicating the origin of electrophoresis or the site of sample, and electronegative end to the right. The extent of the shading of the vertical bands indicates approximately the intensity of the formazan formation. Long lines represent streaking instead of a discrete band. Although the corresponding loci of dehydrogenase activities of various tissues seem to occupy the same positions on the starch gel column, their identity remains to be established.

The results from a study of the homogeneous cell preparations show elearly that a multiplicity of specific dehydrogenases does exist in these preparations (1iig. 2). However, this information does not necessarily rule out the contribution from various cell types in a tissue to this multiplicity.

The omission of diaphorase in the incubation medium for the visualization of

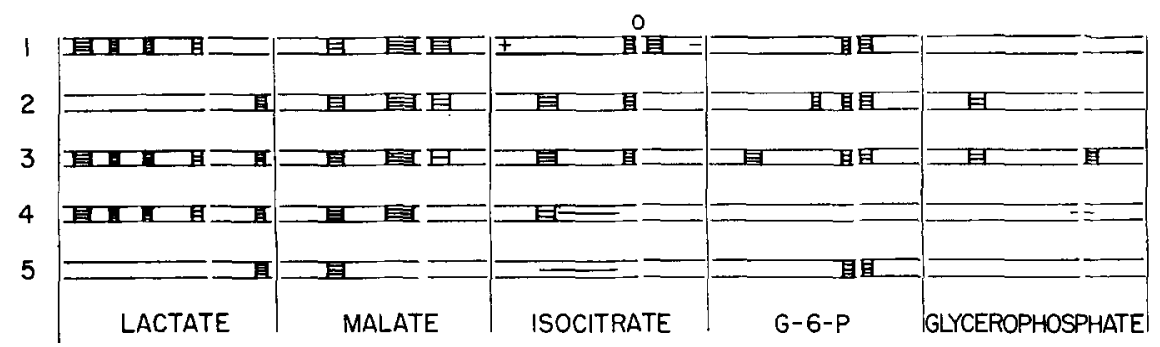

Fig. 1. Dehydrogenases of rat tissue homogenates after fractionation by electrophoresis in starch gel and direct visualization of enzymic activity in the gel. 1 , heart; 2 , liver $; 3$, kidney; 4 , brain; 5 , erythrocytes.

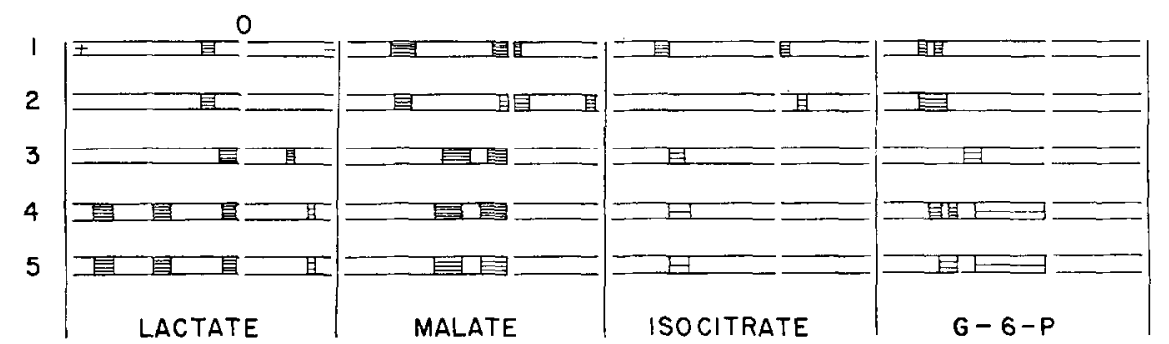

F1G. 2. Dehydrogenases of cytologically homogeneous material. 1, mouse fibroblast cells; 2, mouse ascites lymphoma cells; 3 , human amnion cells; 4 , cells grown from human carcinoma of ovaries; 5 , HeLa cells. 
dehydrogenase activity suggested the possibility that a sufficient amount of this flavoprotein was present in the homogenates and migrated with the enzymes in the starch gel. At the suggestion of Dr. B. Vennesland, three commercially available crystallized lactate dehydrogenase samples were treated in the same manner as the homogenates for electrophoresis and visualization of enzymic artivity. Modifications of the incubation medium were made, however, to leave out I)P or methylene blue and to add diaphorase in various combinations. Positive reduction of the tetrazolium salt occurred only when both DPN and methylene blue were present and the addition of diaphorase was not necessary but did enhance the amount of precipitate. The results indicate that diaphorase was not completely removed by the purification procedure in the preparation of these dehydrogenases. The technique for the visualization of enzymic activity might be used to detect relatirely low levels of diaphorase in dehydrogenase preparations.

One possibility of an artifact in the process of electrophoresis leading to the apparent fractionation of a dehydrogenase was inrestigated. From an initial run of kidney homogenate, three sections of the starch gel column showing strong lactate dehydrogenase artivity were cut out and inserted into three new starch gel columns. After a second electrophoresis, a single band at each of the three corresponding positions indicate rlearly that the difference in the mobility of the three components are real and reproducible, and that the process of electrophoresis did not break up any one of the "omponents to form the other.

Negative results were obtained in attempts to fractionate and visualize dehydrogenases of glucose, succinate, glutamate, $\beta$-hydroxybutyrate, and $\alpha$-ketoglutarate.

\section{DISCCSSION}

The conditions for the preparation of the tissue homogenate, the electrophoretic fractionation, and the detection of enzymic activity as used in this study might be considered to cause the least possible damage 10 the enzymes concerned. The use of sur- face-active agent merely facilitated the preparation of the homogenates but was found to have no effect on the results. Therefore, it is least likely that the multiple loci of enzymic activity on the starch gel column could be the result of breakdown products of enzymes that were originally singular protein molecules. Nevertheless, the phenomenon of the existence of multiple forms of an enzyme from a single source is not yet unequivocally established even though results of this study and the information in the literature seem to suggest that such is the case. This uncertainty is mainly due to the difficulty in proving the absence of modilication or fragmentation of the native enzyme during the experimental procedure.

Although the homogenate was used as such on the filter-paper strip that was inserted into the starch gel column, the material that migrated electrophoretically in the gel was not particulate but soluble. This is supported by the observation that succinale dehydrogenase activity was detected only at the origin. The possibility of the presence of complexes of an enzyme with a substrate or pyridine nucleotide or both in the homogenate and giving rise to molecules of different mobility is negligible because of the necessity for added substrate and pyridine nucleotide in order to visualize the dehydrogenase artivity. The experimental conditions st.rongly suggest that the bands of formazan represent the location of enzymes unassociated with either clectron-transport system or cofactors.

The quantitative aspert of the enzymic artivities as reflected in the intensity of the formazan precipitation in the starch gel column might be noted in brief. Lxperimentally, the intensity of the rolor of a band could range from rear negative to overwhelming depth such as to cause diffused roloration over a long segment of adjacent area. It is always possible then that at rertain enzyme is present at a level below detection under the conditions used rather than being simply absent. The similarity of the patterns of the hands of different tissues as shown in Fig. 1 is of interest.

The multiplicity of dehydrogenases as indicated by the data in this report may be 
applied to the interpretation of previous studies on lactate dehydrogenases from animal organs. Nisselbaum and Bodansky (8) showed differences in the degree of inhibition of lactate dehydrogenases from rabbit organs by the antiserum of this enzyme. Wieland et al. (9) in a recent paper showed that the lactate dehydrogenase from some rat tissues after crystallization may or may not be electrophoretically heterogeneous. It is possible that an antiserum may be obtaincd which inhibits completely one (or two) components of dehydrogenase in the material injected, but will inhibit the enzyme from a particular organ only to the extent of the percentage of this component present in the enzyme preparation. Hence, a difference in inhibition, as observed by the above investigators, could be due to the presence of a particular component in different percentages in each organ.

Kaplan et al. (10) reported, lately, the application of a catalytic technique in a study of the lactate dehydrogenase to a wide variety of animal tissues. They showed a quantitative difference between the dehydrogenases from different tissue in the same animal and the same tissue from different animals. The difference was attributed by them to molecular heterogeneity of the enzyme. However, the presence of multiple lactate dehydrogenases in a single tissue giving an apparent group effect might account for at least some of the differences observed by them.

Shortly after the initial report of this work (1) appeared, Markert and Møller (11) published their work on lactate dehydrogenases using similar methodology and, in general, agreeing with the result of this report.

\section{REFERLNCES}

1. Tsao, M. U., Federation Proc. 18, 341 (1959).

2. Neilanus, J. B., J. Biol. (hem. 199, 373 (1952).

3. Krebs, E. (i., J. Biol. Chem. 200, 471 (1953).

4. Sayre, F. W., and Hisl, B. R., Proc. Soc. Exptl. Biol. Med. 96, 695 (1957).

5. Veseri, E. S., añ Bearn, A. G., J. Clin. Invest. 37, 672 (1958).

6. Wieland, T., and Pflemerer, (i., Biochem. Z. 329, $112(1957)$.

7. Smiтhies, O., Biochem. J. 61, $629(1955)$.

8. Nisselbatim, J. S., and Bodansky, ()., Federation Proc. 18, 294 (1959).

9. Wieland, T., PFleiderer, G., ANi) ORTANDER, F., Biochem. Z. 331, 103 (1959).

10. KaphaN, N. O., Сtotti, M. M., HAMOLSKY, M., AND Bieber, R. E., Science 131, 392 (1960).

11. Markert, C. L., AND Mপ̆iler, F., Proc. Natl. Acad. Sci. U. S. 45, 753 (1959). 